\title{
THE EXPERIENCE OF AUTONOMY WITH DURABLE PRODUCTS
}

\author{
Ortiz Nicolas, Juan Carlos (1); Schoormans, Jan (2) \\ 1: National Autonomous University of Mexico; 2: Delft University of Technology
}

\begin{abstract}
A study to understand the experience of autonomy with durable products was undertaken based on qualitative research. The study involved thirteen participants, who selected a durable product that enhanced autonomy. Using in-depth interviews, the map of experience and interaction properties the experience was studied. Our findings indicate that there are three structures involved in the experience of autonomy: orchestration, control and product integration. The three structures are described in detail. It was also identified that the experience of autonomy enhances positive experiences and stimulates wellbeing. Designers can apply the three structures of autonomy to underscore design decisions.
\end{abstract}

Keywords: Experience design, User centred design, Design education, Psychological needs, User Experience

Contact:

Ortiz Nicolas, Juan Carlos

National Autonomous University of Mexico

Industrial Design

Mexico

juancarlos.ortiz@cidi.unam.mx 


\section{INTRODUCTION}

A three-year child opens a cupboard door, the one that is located at the bottom and he can easily reach. He grabs some pens, colours, a notebook and starts drawing. The child performs all the previous task without the support of an adult person. In some degree, the child is fulfilling his need of autonomy. Research in the field of psychological needs has defined autonomy as: "feeling that you are the cause of your own actions without the intervention of external forces or pressures" (Sheldon, Ellit, Kim and Kasser, 2001). Therefore, the view of autonomy in this research is related to the faculty or power of using one's will (Ryan \& Deci, 2001). Previous research also indicates that autonomy emerges when self-intrinsic goals are congruent to the self. The previous relationship is a major distinction with other concepts such as being independent or in control, these concepts are not necessarily aligned to intrinsic motivations (Ryan \& Deci, 2001).

Needs are important to design in general and user experience (UX) in particular, which points out the relevancy to understand autonomy. Research in psychological needs has demonstrated its fundamental role to explain satisfying events in daily life (Sheldon et al., 2001). In the field of UX similar findings have been identified, the fulfilment of needs is the major source of positive experiences with interactive technology (Hassenzahl, Diefenbach \& Göritz, 2010). This suggest that the more intense the need fulfilment in an experience is, the more positive it is (Hassenzahl, Wiklund-Engblom, Bengs, Hägglund, and Diefenbach, 2015). Therefore, by understanding how needs are fulfilled we can offer detail descriptions of how positive experiences are structured in human-product interaction.

In this research we will focus on understanding the experience of autonomy for a number of reasons. First, autonomy is a salient need that contributes to satisfying events in daily life (Sheldon et al., 2001), and as such, it is expected to be a relevant antecedent for positive experiences in humanproduct interaction. Second, there is limited or inconclusive knowledge on autonomy (Hassenzahl et al., 2010 p. 356). Third, understanding the mechanisms that influence autonomy can be used to design human-product interaction that enhance user's wellbeing (Peters, Calvo, and Ryan, 2018). Fourth, understanding autonomy can be used to involve designers in in-depth discussions associated to psychological needs. Need's fulfilment is a recurrent issue in design, which is generally poorly addressed.

Autonomy is relevant in daily human-product interactions. Many products provide increased autonomy to mainstream consumers. A car navigation system provides autonomy to drivers by guiding them to their destination and avoiding the inconvenience to ask the way to strangers, as was the norm before the widespread use of these digital products. In the field of product design, it was identified that products that were categorised by their owners as 'great' and fulfilled the need of autonomy have a common characteristic: the products excel at their instrumental function and thus aligned with the owners wishes (Ortiz Nicolas, Aurisicchio and Desmet, 2013), however, no further research has been undertaken to thoroughly understand autonomy. Next, there are populations that can benefit from objects that enhance autonomy, to report three: children (to enhance it), people with disabilities (to regain it) and seniors (to maintain it).

Although autonomy is a topic that is relevant for many product categories, it has received extra attention in the field of digital design (Peters et al., 2018). Previous findings in this field have suggested that autonomy can be enhanced by four strategies: 1) As part of interacting with the technology via its interface (e.g. clicking the right button to achieve the desired goal), 2) As part of engaging with technology-enabled tasks (e.g., self-tracking), 3. In relation to the overarching technology-supported behaviour (e.g., exercise) 4. As part of a user's overall life (e.g., travelling). Autonomy is also relevant to design based on particular approaches, for example, autonomy seems relevant to co-design because this design approach seeks to give the power back to users, whom can develop solutions to their problems. The previous findings offer an idea of how autonomy impacts on human-product interaction; however, it is still unclear how it is experienced.

Before introducing the goal of this research, we now address an issue that will help clarify the aim of this study. This research is not related to autonomous products, such as a self-driving car that can move around with little or no human directions. We focus on the person's autonomy. "When people act with autonomy, they act with high willingness and in accordance with their personal goals and values, connecting autonomy to meaning and purpose" (Peters et al., 2018). 
The goal of this research is to thoroughly understand how autonomy is experienced in the humanproduct interaction. This will help us explain how autonomy is fulfilled in the human-product interaction, as well as, to unlock the involved factors. By following this approach, we directly deal with an issue that is complicated to design practice, the fussiness of autonomy, e.g. how does a person experience the need of autonomy in the human product interaction? Furthermore, understanding the experience of autonomy is a first step to suggest strategies that designers can follow when aiming to design for it, e.g. how can designers create products that are aligned with the person's internal motivations?

The present article is structured on five sections. The first, introduces a literature review to identify previous findings related to autonomy. The second, introduces how the study was undertook to understand the experience of autonomy and identify the involved mechanism that enhance it. The third, introduces the findings. The fourth, displays the discussion of the study and, finally, the fifth discloses the conclusions.

\section{LITERATURE REVIEW}

The study of needs is usually carried out in other sciences than design, for instance, in sociology and psychology. Thus, the study of autonomy is diverse, for example, it has been considered as a motivator or construct of psychological wellbeing (Ryff, 1989; Ryan and Deci, 2001). Autonomy has also been studied as a psychological human need (Sheldon et al., 2001; Deci and Ryan, 1987) and as a basic human need that is influenced by culture (Keller, 2012). The emphasis of psychological need is to contrast it with physiological needs such as hunger (Maslow, 1943). A basic human need, on the other hand, stands for its presence in all humans, e.g. universal.

Deci and Ryan (1987 p. 1025) explain that autonomy is fulfilled when "people experience themselves as initiators of their own behaviour; they select desired outcomes and choose how to achieve them. Regulation through choice is characterized by flexibility and the absence of pressure". Other definitions explain that autonomy is "feeling that you are the cause of your own actions without the intervention of external forces or pressures" (Sheldon et al., 2001). Therefore, the faculty or power of using one's will, is fundamental to autonomy (Ryan \& Deci, 2001). Autonomy is therefore related to the concept of identity congruence, which is defined as: "the rated extent to which people pursue their set of personal goals with feelings of intrinsic interest and identity congruence, rather than with feelings of introjected guilt and external compulsion" (Sheldon \& Houser-Marko, 2001). In other words, "Self-concordant goals are those that fulfil basic needs and are aligned with one's true self. These goals are well-internalized and therefore autonomous, and they emanate from intrinsic or identified motivations" (Sheldon \& Elliot 1999 in Ryan \& Deci, 2001, p.157).

Another concept that is relevant for autonomy is perceived control. It is defined as the individual belief that a person can determine her own internal states and behaviours, to influence her environment and/or achieve a desired result (Levenson, 1973). It is therefore expected that perceived control is present when autonomy is fulfilled because being in control impacts on the user to achieve her goals in the human-product interaction. However, control does not equal to autonomy, a person can control his laptop, but it does not mean that they use the laptop to fulfil their intrinsic goals. Deci and Ryan (2001) argue that the opposite to autonomy is being controlled, which has two main characteristics, great rigidity and experiencing the activity as something that a person must do; thus, intention can be involved but the true sense of choice is absent. Autonomy is related to the true sense of choice.

\section{STUDY}

Over a 4-week period, semi-structured interviews were conducted with 13 participants and the aim was to understand the experience of autonomy in human-product interaction. Participants were instructed in advance to selected one product based on the following conditions: they should own and use the product regularly (at least once per week). Participants were also informed that the focus was on selecting a product that enhances autonomy, which was defined based on Sheldon et al., (2001). The targeted products were durable products, such as digital cameras, in comparison to disposable ones, e.g. a plastic bottle that contains water and is discarded after drinking it. To focus on gaining real-world data, the selected products were required to be commercially available. 


\subsection{Methodology}

We established to undertake a qualitative study because it aligns well with our research goal, it is ideal to explore and understand the individual and group meaning that is ascribed to a social or human phenomenon as is the case of autonomy (Creswell, 2013). Our research approach is based on phenomenology, we focus on the study of consciousness through interviews and the durable products that impact on the experience.

\subsection{Sample}

Thirteen participants were part of the study, of whom 6 were men and 7 women. The sample's median age was 26 (Minimum $=24$, Maximum $=34$ ). A snow-sampling technique was used to recruit participants. The participants had no relationship with the design discipline, and they were from a Mexican nationality, residing in the north of the country in Ciudad Juarez.

\subsection{Data collection}

To collect the information an interview session was organised. Prior to the interview, all participants received a selection sheet, which included a definition of autonomy based on Sheldon and colleagues (2001). The sheet also included five printed images in black and white, as examples of durable products, and a rectangle in which the participant wrote down the reasons of her selection. Participants handed in the selection sheet to the interviewer and a picture of the selected product at the beginning of the session, which was conducted in a calm and uninterrupted environment. They permitted audio recordings of the session, which averaged $30 \mathrm{~min}$ in length and were conducted in Spanish. The sessions covered three main activities: (1) To explain the reasons for which the selected product fulfilled the need of autonomy based on product's relevance to the self, activities undertaken with the product and functionality performance. (2) To explore the general and long-term UX with the selected product. The map of experience was the selected tool to assist users in retrospectively reporting how and why their experience with a product has changed over time (See Kujala et al., 2011). Participants received a printed map in a letter sheet, and they reported positive and negative events with the product from the beginning of use to present. When participants completed the task, they were asked to verbally explain the map. (3) To explore the role of interaction in products that fulfil the need of autonomy. We relied upon a set of interaction properties that were developed by Lenz, Diefenbach \& Hassenzahl (2013) to understand the role of interaction in UX. Interaction impacts on UX (Ortiz Nicolás y Aurisicchio, 2011), however, this element is frequently ignored in UX research due to automatization (Lenz et al., 2013). To overcome this limitation, we created a paper survey that included 10 dimensions of interaction properties. Each dimension included two options that were introduced based on written descriptions, for example, for the fluency dimension the two descriptors were: a) the interaction with the product is smooth and fluent; b) the interaction with the product is step by step. Participants selected a property of each dimension based on a yes/no answer and no verbal data was reported. The 10 dimensions that were used to collect data related to interaction are: slow-fast, fluent-step by step, instant-delay, expected-unexpected, constant-variable, high strength-low strength, high mental effort-low mental effort, exact-approximate, intentional-accidental and familiarnovel (See Lenz and Colleagues, 2013).

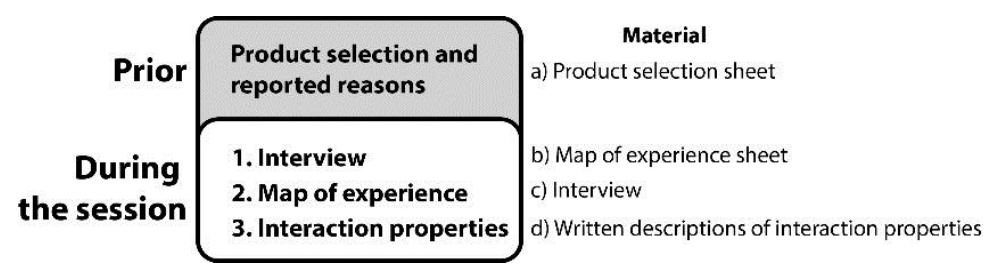

Figure 1. Process and material for each interview session

Figure 1 shows the followed process and material used. The activities undertaken in the session complement the understanding of the experience of autonomy by addressing particular issues (verbal reports, evolution of UX over time and the role of interaction). As a conclusion of the session the participants were informed the research goal and queries were answered. 


\subsection{Data handling}

We relied upon the approach suggested by Fernández Nuñez to analyse qualitative data, which is structured in four steps: a) Collect the information. We have described the process in the previous section; b) Capture, transcribe and order information. The audio recordings were transcribed verbatim and organized based on the discussed themes. c) Code the information. Codes synthesized the categories that concentrate the main findings. The first author iteratively worked through the transcripts to define the categories, which were later discussed with the second author of the article, d) Integrate the information. Relate the categories obtained in the previous step with each other and with the theoretical foundations of the research (see Fernández Nuñez, 2006).

The themes that emerge from the analysis are reported in Section 4. We present quotations from the participants to detail them. It is relevant to report that although we conducted the analysis on full verbatim transcripts that reflected tags, repetitions or pauses were edited, thus, the quotations provided in the following sections were edited for ease of comprehension. Furthermore, the interviews were conducted in Spanish and the selected quotations were translated to English by the first author.

\section{FINDINGS}

We argue that the selected products fulfil the predefined conditions of the study: they are durable and commercial products and enhance the experience of autonomy. Therefore we proceed to undertake the analysis and propose two levels of analysis: (1) Product selection; (2) The constructs of autonomy in human-product interaction.

\subsection{Product selection}

Participants selected the following products: P1. Laptop, P2. Stove, P3 Drill, P4 Laptop, P5. Car, P6. Digital Camera, P7. Bed, P8. Pickup truck, P9 Dental Drill, P11. Software, P12. Laptop, P13. Wrist watch. Participants reported to own the product for a minimum period of 3 months and a maximum of 20 years (5.9 years in average). 11 participants bought the product and 2 received them as a gift. An analysis of the selected products shows that various product categories enhance the experience of autonomy, e.g. laptops, mobile phones, kitchen appliances, tools, software and cars; Most of them, 10 out of 13 , are mobile, i.e. they can be taken by the person or are used as transport.

\subsection{The constructs of autonomy in human-product interaction}

All Participants reported that they required the selected product to carry out their daily activities, which were related to their work and profession, education or personal care. Therefore, the involved activities were relevant to the self. The constructs of autonomy are four (1) Orchestration, (2) Control, (3) Product Integration and (4) Positive Affect.

\subsubsection{Orchestration}

Participants acknowledged that they plan and direct the interaction with the product to achieve a desired outcome which is aligned to their goals. Three issues impact on the orchestration structure: participants' intrinsic motivation is involved; they also assume full responsibility of the humanproduct interaction and complete the involved task or activities in their own way.

Intrinsic motivation. Participants carried out activities that are relevant to the self with the product's support in the day-to-day basis. The activities can be instrumental, making notes in a mobile phone, or hedonic as the enjoyment experienced when a person cooks for his family.

P10 "With my cell phone I can perform multiple tasks, thus, I cannot leave my house without my phone. It is practically my 'notebook'. With it I make my class notes, complete tasks with applications (Word, Power Point) and scan documents to be able to study for exams."

Self-responsibility. All participants assumed full responsibility of the human-product interaction. This is another sign that indicates that participants plan and direct the interaction.

P4 "With this laptop I can establish the limits of use, visit or share websites that I like. I can also meet my needs in terms of use, process."

My own way. Participants relied upon their skills and adjusted the product to use it in their own terms. The reported skills were associated to the involved activities with a particular product, e.g. creating furniture with the support of a drill. The adjustments were generally focused on the products' instrumental functions. 
P1. "I use different programs [in a laptop] to fulfil my needs. In this case I am already using the tools in the way that best suits me. With the Word software, for example, I can create a table to grade a group of students. Another example could be the use of Mendeley, in which I can select the articles that I am going to read or the articles that I have already read, make folders to organise articles based on a particular purpose."

\subsubsection{Control}

Participants referred to the control that they have with the product to perform an activity. There is also an alignment between activities that users undertake and the product's performance. Finally, four common interaction attributes were involved with the selected products: expected, fast, instant and constant.

Control over the product. Participants developed control over the situation in which they were involved with the support of the selected products.

P9 "I have to use the dental drill in a correct way. I can control how I move it and I can control the cutting in the patient's tooth. I feel self-sufficient to have the skills to manage the drill and control its movements. To perform well a task for the patient's benefit."

Participants also recognised that context plays a role, for instance, when the person does not have any control of the context the experience of autonomy diminishes, as in the case of a natural disaster.

Alignment towards fulfilling the activity. All participants reported that the main goal was to fulfil the desired activity. Thus, there is an alignment between the user's goal and the product's reaction.

P6. "I check my camera to confirm that all the settings are well established, and after that into the object or people that I will take photographs of".

Interaction qualities. The interaction properties that were frequently involved with products that enhance autonomy are: expected, fast, instant and constant. We introduce the written description that were used in the survey because no verbal data was collected:

The product's reaction is expected, I pedal on my bike and it moves (reported by 13 users).

The product's reaction is fast, I swipe the photos on my phone, and it reacts according to the speed $(12 / 13)$.

The product's reaction is instant, I took a photograph and immediately see the result (12/13).

The product's reaction is constant, it always delivers the same result (11/13).

\subsubsection{Product integration}

Participants acknowledged that the selected product is well integrated in their functions, it is reliable, and adjustable.

Reliable. The products are consistently good. They deliver the desired and expected outcome. Thus, the user trusts the selected product.

P13: "I trust that my watch marks the time accurately, therefore, I can trust the time that I take for each of my planned activities".

Adjustable. Participants reported to adjust characteristics of the products to perform the involved activities, e.g. to adjust the driver's seat in a car.

P12: "I can adjust many options in my laptop, I can adjust the angle of the screen, its brightness, the volume of the speakers, activate particular shortcuts, to give some examples".

\subsubsection{Positive affect}

All participants describe the experience with the product based on positive adjectives: satisfactory, good, pleasant, and very good. Furthermore, all participants acknowledged that fulfilling autonomy impacts on their wellbeing.

Map of experience. All the maps generated by the participants showed that the current experience was positive. Two general trends were identified: a) neutral to positive and b) negative to positive. The most frequent reported path was from negative to positive. Eight participants reported to have a negative experience with the product before and during first contact. The experience changed when participants developed skills or learnt how to use the selected product. An explanation is introduced:

$P 9$ "At first it was negative because I was afraid of the drill's high speed. I was afraid of cutting someone's tongue. Then, I realised that it was not easy to cut someone's tongue. With time I developed my skills to use the drill and it has been very positive experience since then." 
Wellbeing. All participants acknowledged that fulfilling the need of autonomy impacts on their wellbeing.

$P 7$ "Yes, autonomy stimulates wellbeing, because autonomy reminds you of what you want, it reminds you of what you have, it reminds you that everything that happens around affects you in the end ".

\section{DISCUSSION}

The goal of this research was to develop a thorough understanding of the experience of autonomy in the context of human-product interaction. Our findings indicate that it is structured on three main constructs that have been described in detail: orchestration, control and product integration. Therefore, we have overcome the limitations of previous research.

Figure 2 integrates the findings of this research. The experience of autonomy is orchestrated by the user, the interaction allows the user to control the product, and the product is well integrated. The experience with the products is positive and enhances user's wellbeing.

The experience of autonomy is structured on a one to one relationship: a user with a product. It is strongly associated to undertaking activities that are relevant to the self, i.e. intrinsic motivation. Selfresponsibility is associated to directing the product based on the user's skills and commands. Our findings are in line with results of research in the field of psychological needs, the faculty or power of using one's will, is fundamental to autonomy (Ryan \& Deci, 2001) and to identity congruence, which is related to the pursuing of the user's personal goals, which involve feelings of intrinsic interest and identity congruence (Sheldon \& Houser-Marko, 2001). The findings also show, that at the time of the interview, participants had already developed the skills to use the selected product in their own terms. In relation to interaction, participants reported to develop control over the situation in which they were involved with the support of the products. This is also in line with the idea of perceived control, which is the individual belief that a person can determine her own internal states and behaviours, to influence her environment and/or achieve a desired result (Levenson, 1973). The results of this research indicate that users influence the environment with the support of a product. The collected data related to interaction properties suggest that using the product is fluent and particular properties were identified: expected, fast, instant and constant. The product is well-integrated, it is reliable and adjustable. The fulfilment of autonomy, with the support of a product, enhances a positive experience and impacts on the users' wellbeing.

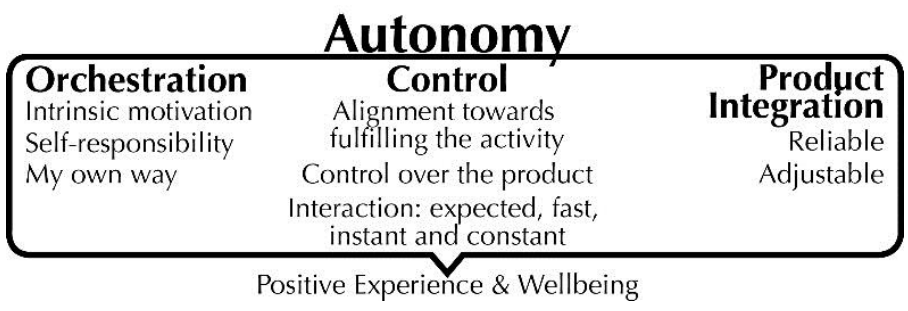

Figure 2. The constructs of autonomy in human-product interaction

We study the experience of autonomy with the support of tools that have been developed in the UX field: the map of experience (Kujala et al., 2011), interaction attributes (Lenz et al., 2013) and an indepth interview. The use of the tools was fundamental to understand the experience of autonomy. The map of experience helped us understand that, at the moment of the interview, the experience with the selected product was positive. The map, however, also supported participants to report that in various cases there was a period of adaptation between the user and the product. The adaptation seems to be mediated by the development of relevant skills that impact on the human-product interaction. The interviews, on the other hand, helped us understand the nuances of the experience. Finally, interaction attributes and their description were a first attempt to study its role in a particular experience. The results suggest that when interacting with the selected objects the user's aim to achieve a particular goal/activity. Thus, it resembles the embodied interaction mode suggested by Ihde, in this mode the object is fully embodied into the experience and thus it fades out of focus (Ihde in Wendt, 2015, p.88). In conclusion, the tools that have been independently developed in the field of UX are effective to gain a broader understanding of the experience of autonomy. This is important considering that language is a recurrent mean to understand human experience (Riessman, 1993). We encourage other scholars to rely upon different means to study UX. 
The finding of this research confirms that need fulfilment is an element that impacts on positive experiences (Hassenzahl et al., 2010; Hassenzahl et al., 2015). In the case of autonomy, the positive experience emerges when there is a match between user commands, based on activities that are relevant to the self, with the product's reaction. The expected outcome is the user's fulfilment of her desired goal. Our findings also show that the fulfilment of autonomy impacts on user wellbeing. Previous research has questioned current approaches to enhance wellbeing in the field of UX because they face a substantial gap between theoretical frameworks and practical and actionable design strategies (Peters et al., 2018), for example, the fulfilment of universal needs (Hassenzahl et al., 2010). Our results indicated that autonomy enhances wellbeing and we suggest that the constructs of autonomy can inform design strategies that stimulate wellbeing. It is still unclear, however, what is the best approach to define actionable design strategies to promote wellbeing.

The results of the study confirm that autonomy emerges when self-intrinsic goals are accomplished with a product's support. Self-intrinsic goals are different from other concepts such as being independent or in control, these conditions are not equivalent to intrinsic motivations (Ryan \& Deci, 2001). Therefore, a strategy to design for autonomy is to identify the intrinsic goal that users seeks to accomplish with particular products and align design decisions to complete the particular goal. Peters et al. (2018) have suggested that the decisions can inform four levels of the human-product interaction: 1. As part of interaction, 2. As part of task, 3. As part of behaviour, and 4. As part of a user's overall life. Our results indicate that there is hierarchy that can direct design decisions, i.e. intrinsic goals. This is because an object that enables an expected, fast, instant and constant interaction does not necessarily enhances autonomy. Similarly, clicking a button does not necessarily helps a person fulfil her need of autonomy. The guiding factor to fulfil autonomy is strongly related to intrinsic goals.

Needs are relevant to design practice. There is a common believe, however, that designers automatically satisfy them through their work. Reflecting on the issue may help designers acknowledge that is not always the case, consider for example that commercial projects are defined based on market goals, e.g. selling more goods than the previous year. This goal does not align with fulfilling human needs because they have a saturation point (Baudrillard, 1981). In other field, consumer culture, it has been reported that consumers are heroes or dupes. They are heroes when they "sovereign over their own desires, and then, through market forces, over the institutions whose profits depend on satisfying those desires with commodities" (Slater, 1997, p. 49). Consumers are dupes and "targets for intervention by advertising, marketing, retailing, etc. the further they fall from the ideal of rationality and autonomy, the more contemptuous the characterization of them becomes" (Slater, 1997, p. 58). It is, thus, valuable to the design discipline to study needs in-depth to avoid their trivialisation. Training designers to design for the experience of autonomy in the human-product interaction can support critical thinking in relation to needs, help designers recognise autonomy's relevance to the project at hand, and select it as target when appropriated.

A limitation of this study is associated to the involved population, young adults. It could be interesting to undertake a study that involves other populations, e.g. people with disabilities, or professional designers to further understand the experience of autonomy. Potential lines of research are: to undertake a study with products that previous research has reported as enhancers of autonomy e.g. robots (Fosch-Villaronga and Özcan, 2019); to understand the frontiers of positive experiences based on the fulfilment of autonomy. The downside of human-product experiences can be that consumers become extremely dependent on a particular object. Thus, a study focused on addictive technology and the involved needs could be a mean to identify if the fulfilment of autonomy is present. The fulfilment of needs enhances positive experiences; however, it is unclear if this also applies to addictive technology. We did not review this issue in our study; finally, it could be tested if self-determination theory is relevant to design, self-determination is structured on the fulfilment of three needs: autonomy, competence and relationship (Ryan \& Deci, 2001; Peters et al., 2018). Similar studies, to the introduced in this article, can be undertaken to understand the other two needs: competence and relationship. The new knowledge may inform strategies that enhance self-determination through the design practice. 


\section{CONCLUSION}

The article introduces a thorough understanding of the experience of autonomy in the context of human-product interaction. The experience of autonomy is based on a one to one relationship: a user and a product. Autonomy is strongly associated to intrinsic motivations, those that are relevant to the self. Users acknowledge self-responsibility because they direct the human-product interaction and rely upon their skills and knowledge to direct the interaction with a product. Furthermore, users can adjust the product to fit their characteristics and perform the task in their own way. In terms of interaction participants reported to develop control over the situation in which they are involved with the support of the product. It was also identified that the interaction with the product is unobstructed and specific properties were shared among the different selected products: expected, fast, instant and constant. The product is well-integrated, reliable and adjustable. The fulfilment of autonomy in the human-product interaction enhances a positive experience and impacts on the users' wellbeing.

\section{REFERENCES}

Baudrillard, J. (1981), El sistema de los objetos, Siglo XXI, Ciudad de México.

Creswell, J.W. and Creswell, J.D. (2013), Research design: Qualitative, quantitative, and mixed methods approaches, Sage publications, London.

Deci, E.L. and Ryan, R.M. (1987), "The support of autonomy and the control of behavior", Journal of personality and social psychology, Vol. 53 No. 6, pp. 1024.

Fernández, L. (2006), “¿ Cómo analizar datos cualitativos”, Butlletí LaRecerca, Vol. 6, pp. 1-13.

Fosch-Villaronga, E. and Özcan, B. (2019), "The Progressive Intertwinement Between Design, Human Needs and the Regulation of Care Technology: The Case of Lower-Limb Exoskeletons", International Journal of Social Robotics, pp. 1-14.

Hassenzahl, M., Diefenbach, S. and Göritz, A. (2010), "Needs, affect, and interactive products-Facets of user experience", Interacting with computers, Vol. 22 No. 5, pp. 353-362.

https://doi.org/10.1016/j.intcom.2010.04.002.

Hassenzahl, M., Wiklund-Engblom, A., Bengs, A., Hägglund, S. and Diefenbach, S. (2015), "Experienceoriented and product-oriented evaluation: psychological need fulfillment, positive affect, and product perception", International journal of human-computer interaction, Vol. 31 No. 8, pp. 530-544. https://doi.org/10.1080/10447318.2015.1064664.

Keller, H. (2012), "Autonomy and relatedness revisited: Cultural manifestations of universal human needs", Child Development Perspectives, Vol. 6 No. 1, pp. 12-18. https://doi.org/10.1111/j.17508606.2011.00208.x.

Kujala, S., Roto, V., Väänänen-Vainio-Mattila, K., Karapanos, E. and Sinnelä, A. (2011), "UX Curve: A method for evaluating long-term user experience", Interacting with Computers, Vol. 23 No. 5, pp. 473-483. DOI: 10.1016/j.intcom.2011.06.005.

Lenz, E., Diefenbach, S. and Hassenzahl, M. (2013), "September. Exploring relationships between interaction attributes and experience", Proceedings of the 6th International Conference on Designing Pleasurable Products and Interfaces, ACM, pp. 126-135. http://dx.doi.org/10.1145/2513506.2513520

Levenson, H. (1973), "Multidimensional locus of control in psychiatric patients", Journal of consulting and clinical psychology, Vol. 41 No. 3, pp. 397. http://dx.doi.org/10.1037/h0035357.

Maslow, A.H. (1943), "A theory of human motivation", Psychological review, Vol. 50 No. 4, pp. 370.

Ortiz Nicolás, J.C. and Aurisicchio, M. (2011), "The scenario of user experience", DS 68-7: Proceedings of the 18th International Conference on Engineering Design (ICED 11), Impacting Society through Engineering Design, Vol. 7: Human Behaviour in Design, Lyngby/Copenhagen, Denmark, 15.-19.08. 2011.

Ortiz Nicolás, J.C., Aurisicchio, M. and Desmet, P.M.A. (2013), "How users experience great products", The 5th International Congress of International Association of Societies of Design Research, Tokyo Japan.

Peters, D., Calvo, R.A. and Ryan, R.M. (2018), "Designing for Motivation, Engagement and Wellbeing in Digital Experience", Frontiers in Psychology, Vol. 9.

Riessman, C.K., 1993. Narrative analysis (Vol. 30). California: Sage.

Ryan, R.M. and Deci, E.L. (2001), "On happiness and human potentials: A review of research on hedonic and eudaimonic well-being”, Annual review of psychology, Vol. 52 No. 1, pp. 141-166. https://doi.org/10.1146/annurev.psych.52.1.141.

Ryff, C.D. (1989), "Happiness is everything, or is it? Explorations on the meaning of psychological well-being", Journal of personality and social psychology, Vol. 57 No. 6, pp. 1069. doi: 10.1037/0022-3514.57.6.1069.

Sheldon, K.M. and Houser-Marko, L. (2001), "Self-concordance, goal attainment, and the pursuit of happiness: Can there be an upward spiral?", Journal of Personality and Social Psychology, Vol. 80 No. 1, pp. 152165. https://doi.org/10.1037//0022-3514.80.1.152. 
Sheldon, K.M., Elliot, A.J., Kim, Y. and Kasser, T. (2001), "What is satisfying about satisfying events? Testing 10 candidate psychological needs", Journal of personality and social psychology, Vol. 80 No. 2, pp. 325. https://doi.org/10.1037//O022-3514.80.2.325.

Slater, D. (1997), Consumer culture and modernity, Polity Press, London, pp. 1-224.

Wallston, K.A., Wallston, B.S., Smith, S. and Dobbins, C.J. (1987), "Perceived control and health", Current Psychology, Vol. 6 No. 1, pp. 5-25.

Wendt, T. (2015), Design for Dasein: Understanding the design of experiences, Thomas Wendt, California. 